\title{
Of
Of FOUNDRY ENGINEERING \\ Optimization of Micro-Alloying Elements for Mechanical Properties in Normalized Cast Steel Using Taguchi Technique
}

\author{
B. Chokkalingam ${ }^{\text {a, *, V. Raja }}{ }^{\text {a }}$, J. Anburaj ${ }^{\text {b }}$, R. Immanual a, M. Dhineshkumar ${ }^{\text {a }}$ \\ ${ }^{a}$ Department of Mechanical Engineering, Sri Ramakrishna Institute of Technology, Coimbatore-641010, India. \\ ${ }^{b}$ Department of Metallurgical Engineering, PSG College of Technology, Coimbatore-641004, India. \\ *Corresponding author. E-mail address: bchokkalingam@gmail.com.
}

Received 27.01.2017; accepted in revised form 23.04.2017

\begin{abstract}
In this study, Taguchi method is used to find out the effect of micro alloying elements like vanadium, niobium and titanium on the hardness and tensile strength of the normalized cast steel. Based on this method, plan of experiments were made by using orthogonal arrays to acquire the data on hardness and tensile strength. The signal to noise ratio and analysis of variance (ANOVA) are used to investigate the effect of these micro alloying elements on these two mechanical properties of the micro alloyed normalized cast steel. The results indicated that in the micro alloyed normalized cast steel both these properties increases when compared to non-micro-alloyed normalized cast steel. The effect of niobium addition was found to be significantly higher to obtain higher hardness and tensile strength when compared to other micro alloying elements. The maximum hardness of $200 \mathrm{HV}$ and the maximum tensile strength of $780 \mathrm{~N} / \mathrm{mm}^{2}$ were obtained in $0.05 \% \mathrm{Nb}$ addition micro alloyed normalized cast steel. Micro-alloyed with niobium normalized cast steel have the finest and uniform microstructure and fine pearlite colonies distributed uniformly in the ferrite. The optimum condition to obtain higher hardness and tensile strength were determined. The results were verified with experiments.
\end{abstract}

Keywords: Normalized cast steel, Micro-alloying, Mechanical properties, Taguchi method, Microstructure

\section{Introduction}

Complicate shapes can be produced easily in a single step process in the cast steel. Depending on the service requirements of the component, selection of a suitable composition is easier from many compositions available in the cast steel. These advantages make the steel castings more suitable for various applications. The demand for steel castings are also ever increasing due to its wider applications like in railways, automobiles, heavy steel plants, cement industries, sugar industries, paper industries, chemical plants, fertilizer plants, oil refineries and nuclear applications. However the mechanical properties of cast steel are lower when compared to wrought steels. Hence further improvements in mechanical properties in the steel castings are required to meet the present critical applications. This can be done either by means of alloy additions or heat treatment or by employing both. Among the alloying, micro alloying $[1,4]$ is a method in which the individual

elements such as vanadium, niobium and titanium can be added in the base steel.

The maximum addition of each micro alloying element is $0.1 \%$ and the overall micro alloying addition of all the elements combined together should not exceed $0.2 \%$. The study on the effects of micro-alloying additions in the cast steel is required for further development of this method. The improved mechanical 
properties are one of the main requirements of micro-alloying additions. In this work, increase in hardness and tensile strength through micro alloying is studied. The micro-alloy additions that influence the hardness and tensile strength of cast steel are to be identified and have to be added accordingly. Statistical methods can be used for the identification of significant control parameters for optimization.

The Taguchi method is one such method which is used in this paper to study the hardness and tensile strength of the normalized micro-alloyed cast steel. This method consists of using a minimum number of experiments with the aim of maximizing or minimizing as per the requirement of the objective function of the experiment. The major advantage of the Taguchi method is minimum variability around the target value with minimum experimental cost. Moreover the optimum working conditions determined in the experimental work can also be used in the bulk production also. Generally Taguchi design is a systematic approach to optimize the specific requirement with minimum cost.

Hence in this paper, the Taguchi experimental design and ANOVA methods were used to analyze the effects of microalloying on hardness and tensile strength in the normalized cast steel. The optimum set of alloy additions was obtained by using signal to noise ratios.

\section{Experimentation}

\subsection{Melting and Heat treatment}

Low carbon cast steel was melted in a $50 \mathrm{~kg}$ basic lined induction furnace as shown in Fig.1. Initially mild steel scrap was melted and finally ferro-manganese and ferro-silicon were added into the base metal to adjust the composition. After melting the metal, slag was removed from the top layer of the molten steels. Subsequently the micro-alloying additions of ferro-vanadium, ferro-niobium and ferro- titanium were carried out. Compositional analysis was done by using a vacuum spectrometer. The chemical compositions of trials are given in Table.1 for all the heats.

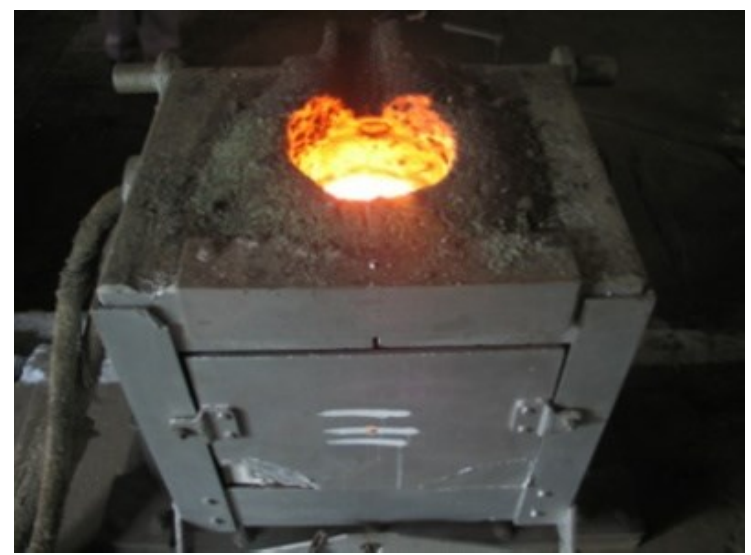

Fig. 1. Induction furnace
Table 1.

Chemical composition of trials

\begin{tabular}{ccccccccc}
\hline $\begin{array}{c}\text { Trial } \\
\text { No }\end{array}$ & $\mathrm{C}$ & $\mathrm{Si}$ & $\mathrm{Mn}$ & $\mathrm{P}$ & $\mathrm{S}$ & $\mathrm{V}$ & $\mathrm{Nb}$ & $\mathrm{Ti}$ \\
\hline 1 & 0.23 & 0.42 & 1.2 & 0.02 & 0.03 & 0 & 0 & 0 \\
\hline 2 & 0.23 & 0.43 & 1.2 & 0.02 & 0.03 & 0 & 0 & 0.025 \\
\hline 3 & 0.24 & 0.41 & 1.3 & 0.02 & 0.03 & 0 & 0.05 & 0 \\
\hline 4 & 0.24 & 0.41 & 1.2 & 0.02 & 0.03 & 0 & 0.05 & 0.025 \\
\hline 5 & 0.23 & 0.42 & 1.1 & 0.02 & 0.03 & 0.1 & 0 & 0 \\
\hline 6 & 0.23 & 0.43 & 1.2 & 0.02 & 0.03 & 0.1 & 0 & 0.025 \\
\hline 7 & 0.22 & 0.41 & 1.3 & 0.02 & 0.03 & 0.1 & 0.05 & 0 \\
\hline 8 & 0.22 & 0.42 & 1.1 & 0.02 & 0.03 & 0.1 & 0.05 & 0.025 \\
\hline
\end{tabular}

Using the literature [3-9] as reference vanadium, niobium and titanium additions were selected. Vanadium level was maintained at $0.10 \%$, niobium and titanium levels were maintained at $0.05 \%$ and $0.025 \%$ respectively. All the heats were tapped at $1610^{\circ} \mathrm{C}$ and deoxidizers like aluminium and calcium silicide were added in the ladle itself. The prepared Y block $\mathrm{CO}_{2}$ sand moulds are shown in Fig.2. Then the liquid metal was poured into them. The normalizing heat treatment was done by heating the test bars from ambient temperature up to $920^{\circ} \mathrm{C}$ in a muffle furnace and remained at this temperature for 2 hours. Then, they were removed from the furnace and air cooled up to the ambient temperature.

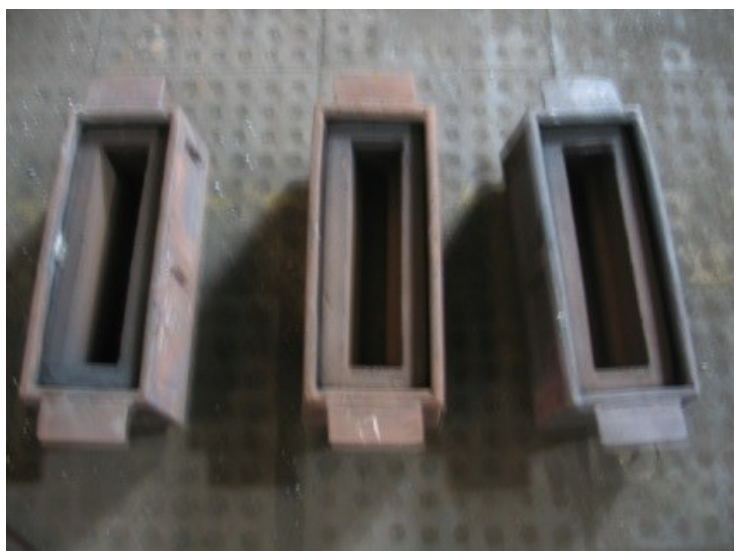

Fig. 2. Y block sand moulds

\subsection{Taguchi Design}

Factorial design of experiment requires larger number of experiments involving a set of selected factors with different combinations and levels among them. All possible combinations of the selected set of factors are to be analyzed in a full factorial design, whereas the Taguchi design [10-14] uses only a small set of experiments from those combinations. Taguchi design provides the information on influence of individual elements on the objective function of the experiment. This experimental design involves orthogonal arrays to organize the experiments with varied levels of the selected factors. It gives the information of the objective function with a minimum number of experiments and saves time as well as resources to conduct the experiments. The major steps in the Taguchi experimental design are selection 
of the objective function, identification of the controllable factors ,selection of the level of controllable factors, selection of orthogonal array, conduction of experiments, analysis of the data, determine the optimum level of factors and confirmation of the experiment.

\subsection{Selection of the objective function}

The main objective of the Taguchi method is to produce quality product at the lowest cost. The first step is to determine the quality characteristic to be optimized. In this work, the optimum addition of micro-alloying elements to improve the hardness and tensile strength in the normalized micro alloyed cast steel is to be determined.

\subsection{Identification of the controllable factors}

The factors affecting the product quality can be divided into controllable factors and noise factors in Taguchi's design. The control factors are set by the experimenter and are easily adjustable whereas the noise factors are uncontrollable factors and cannot be eliminated in the experiment. The control factors determine the quality characteristics of the product. The microalloying elements vanadium, niobium and titanium were selected as controllable factors in this work.

\subsection{Selection of the level of controllable factors}

A factor's effect is evaluated by using a minimum two levels of that factor. The other factors in that experiment were also kept at two levels during the conduct of the experiment. In this experimental work all the three micro alloying elements vanadium, niobium and titanium were maintained at zero at first level. In this method one of the trials in the experiment gives the hardness and tensile strength of the non-micro-alloyed normalized cast steel. The second levels of these elements were kept as vanadium $0.10 \%$, niobium $0.05 \%$ and titanium $0.025 \%$ respectively The selected three factors with their two levels are shown in Table. 2

Table 2 .

Levels of the variables used in the experiment

\begin{tabular}{rccc}
\hline \multirow{2}{*}{ Levels } & \multicolumn{3}{c}{ Variables } \\
\cline { 2 - 4 } & A: Vanadium & B: Niobium & C:Titanium \\
\hline 1 & 0 & 0 & 0 \\
\hline 2 & 0.10 & 0.05 & 0.025 \\
\hline
\end{tabular}

$\mathrm{A}, \mathrm{B}$ and $\mathrm{C}$ parameter designation

\subsection{Selection of orthogonal array}

The orthogonal array is a format which gives the information to conduct the minimum number of experiments. The maximum details of the selected factors and their influence on the objective function of the experiment can be obtained using these orthogonal arrays $[10,11]$. The $\mathrm{L}_{8}$ orthogonal array was selected for this study among the many available standard orthogonal arrays. The experiments were conducted to identify the influence of the three micro-alloying elements each at two levels. The layout of $\mathrm{L}_{8}$ orthogonal array is given in Table 3.

Table 3.

The $\mathrm{L}_{8}$ orthogonal array

\begin{tabular}{cccccccc}
$\begin{array}{c}\text { Experiment } \\
\text { number }\end{array}$ & A & B & AB & C & BC & AC & $\mathrm{S} / \mathrm{N}$ \\
\hline 1 & 1 & 1 & 1 & 1 & 1 & 1 & $\mathrm{~S} / \mathrm{N}_{1}$ \\
\hline 2 & 1 & 1 & 1 & 2 & 2 & 2 & $\mathrm{~S} / \mathrm{N}_{2}$ \\
\hline 3 & 1 & 2 & 2 & 1 & 1 & 2 & $\mathrm{~S} / \mathrm{N}_{3}$ \\
\hline 4 & 1 & 2 & 2 & 2 & 2 & 1 & $\mathrm{~S} / \mathrm{N}_{4}$ \\
\hline 5 & 2 & 1 & 2 & 1 & 2 & 1 & $\mathrm{~S} / \mathrm{N}_{5}$ \\
\hline 6 & 2 & 1 & 2 & 2 & 1 & 2 & $\mathrm{~S} / \mathrm{N}_{6}$ \\
\hline 7 & 2 & 2 & 1 & 1 & 2 & 2 & $\mathrm{~S} / \mathrm{N}_{7}$ \\
\hline 8 & 2 & 2 & 1 & 2 & 1 & 1 & $\mathrm{~S} / \mathrm{N}_{8}$ \\
\hline \multicolumn{7}{c}{ Process parameters A - Vanadium, B- Niobium, } \\
C- Titanium, S/N- Signal to noise ratio \\
\hline \multicolumn{7}{c}{}
\end{tabular}

\subsection{Signal to Noise Ratio}

The control factors and their contribution level of variations in the experiment are to be identified. The experimental data is transformed into $\mathrm{S} / \mathrm{N}$ ratio to measure the variation level of factors. There are three types of $\mathrm{S} / \mathrm{N}$ ratios available in Taguchi's design $[10,11]$. They are lower is better, nominal is the best and higher is better. In this experimental work, the main objective is to increase the hardness and tensile strength of the normalized cast steel. Therefore higher is better characteristic is selected which is given as in equation (1):

$S / N=-10 \log \left[\frac{1}{R} \sum_{i=1}^{R} \frac{1}{y_{i}^{2}}\right]$

Where $\mathrm{R}$ is the number of hardness/tensile strength data sets which is equal to 16 and $\mathrm{y}_{\mathrm{i}}$ is the hardness/tensile strength of the $\mathrm{i}^{\text {th }}$ data set. Tensile strength tests were done in a MICROTEK micro tensile strength testing machine. Hardness tests were performed on polished surfaces of the samples using a Zwick hardness tester using an indentation load of $10 \mathrm{~kg}$. The measured hardness and tensile strength values of the non-micro-alloyed and micro-alloyed normalized cast steels as well as their $\mathrm{S} / \mathrm{N}$ ratios for the experimental trials are shown in Table.4. 
Table 4

Experimental results of the $\mathrm{L}_{8}$ orthogonal array

\begin{tabular}{|c|c|c|c|c|c|c|c|c|c|c|c|c|}
\hline \multirow[b]{2}{*}{ Trial no } & \multicolumn{6}{|c|}{ Process parameters } & \multicolumn{3}{|c|}{ Hardness } & \multicolumn{3}{|c|}{ Tensile strength } \\
\hline & A & B & $\mathrm{AB}$ & $\mathrm{C}$ & $\mathrm{BC}$ & $\mathrm{AC}$ & $\begin{array}{c}\mathrm{H}_{1} \\
(\mathrm{HV})\end{array}$ & $\begin{array}{c}\mathrm{H}_{1} \\
(\mathrm{HV})\end{array}$ & $\mathrm{S} / \mathrm{N}(\mathrm{dB})$ & $\begin{array}{c}\mathrm{TS}_{1} \\
\mathrm{~N} / \mathrm{mm}^{2}\end{array}$ & $\begin{array}{c}\mathrm{TS}_{2} \\
\mathrm{~N} / \mathrm{mm}^{2} \\
\end{array}$ & $\mathrm{~S} / \mathrm{N}(\mathrm{dB})$ \\
\hline 1 & 1 & 1 & 1 & 1 & 1 & 1 & 175 & 176 & 44.88 & 650 & 660 & 56.32 \\
\hline 2 & 1 & 1 & 1 & 2 & 2 & 2 & 185 & 188 & 45.41 & 700 & 680 & 56.77 \\
\hline 3 & 1 & 2 & 2 & 1 & 1 & 2 & 200 & 198 & 45.97 & 780 & 790 & 57.89 \\
\hline 4 & 1 & 2 & 2 & 2 & 2 & 1 & 186 & 186 & 45.39 & 722 & 722 & 57.17 \\
\hline 5 & 2 & 1 & 2 & 1 & 2 & 1 & 186 & 186 & 45.39 & 750 & 760 & 57.55 \\
\hline 6 & 2 & 1 & 2 & 2 & 1 & 2 & 174 & 176 & 44.86 & 699 & 699 & 56.88 \\
\hline 7 & 2 & 2 & 1 & 1 & 2 & 2 & 190 & 194 & 45.66 & 760 & 770 & 57.67 \\
\hline 8 & 2 & 2 & 1 & 2 & 1 & 1 & 175 & 178 & 44.93 & 710 & 720 & 57.08 \\
\hline
\end{tabular}

\section{Results and Analysis}

\subsection{Mean response}

The average value for each factor at different levels is referred as mean response. The average values of $\mathrm{S} / \mathrm{N}$ data and hardness data are given in Table 5 and Table 6 respectively. The $\mathrm{S} / \mathrm{N}$ ratio and mean response for the factors are shown in the Fig. 3 and Fig. 4 respectively. The average values of $\mathrm{S} / \mathrm{N}$ data and tensile strength data are given in Table 7 and Table 8 respectively. The $\mathrm{S} / \mathrm{N}$ ratio and mean response for the factors are shown in the Fig.5 and Fig. 6 respectively. In this experiment, the level which gives the maximum hardness and tensile strength is the optimum level for that factor.

Table 5 .

Average values of $\mathrm{S} / \mathrm{N}$ data (hardness)

\begin{tabular}{lccc}
\hline & \multirow{2}{*}{$\begin{array}{c}\text { Process } \\
\text { parameters }\end{array}$} & \multicolumn{2}{c}{ Average values of hardness } \\
\cline { 2 - 4 } & $\mathrm{A}$ & Level 1 & Level 2 \\
\cline { 2 - 4 } & $\mathrm{B}$ & 45.42 & 45.21 \\
\cline { 2 - 4 } Hardness & $\mathrm{AB}$ & 45.14 & 45.49 \\
\cline { 2 - 4 } (S/N data) & $\mathrm{C}$ & 45.22 & 45.40 \\
\cline { 2 - 4 } & $\mathrm{BC}$ & 45.16 & 45.15 \\
\cline { 2 - 4 } & $\mathrm{AC}$ & 45.15 & 45.46 \\
\cline { 2 - 4 } & & &
\end{tabular}

Table 6.

Average values of mean data (Hardness)

\begin{tabular}{lccc}
\hline & $\begin{array}{c}\text { Process } \\
\text { parameters }\end{array}$ & \multicolumn{2}{c}{ Average values of hardness } \\
\cline { 2 - 4 } & $\mathrm{A}$ & Level 1 & Level 2 \\
\cline { 2 - 4 } & $\mathrm{B}$ & 186.8 & 182.4 \\
\cline { 2 - 4 } $\begin{array}{l}\text { Hardness } \\
\text { (mean data) }\end{array}$ & $\mathrm{AB}$ & 180.8 & 188.4 \\
\cline { 2 - 4 } & $\mathrm{C}$ & 182.6 & 186.5 \\
\cline { 2 - 4 } & $\mathrm{BC}$ & 188.1 & 181.0 \\
\cline { 2 - 4 } & $\mathrm{AC}$ & 181.5 & 187.6 \\
\hline
\end{tabular}

It is clear from Fig. 3 and Fig.4 that the factors A, B, C at the levels $A_{1}, B_{2}$ and $C_{1}$ are the best choices to obtain the higher hardness. The Fig.5 and Fig. 6 reveals that the factors A, B, C at the levels $A_{2}, B_{2}$ and $C_{1}$ are the best choices to obtain the higher tensile strength.

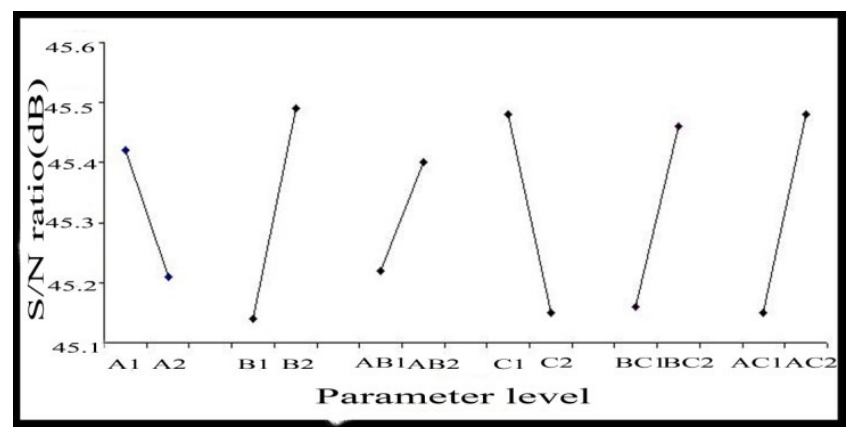

Fig. 3. Average values of $\mathrm{S} / \mathrm{N}$ ratios for each parameter at different levels(Hardness)

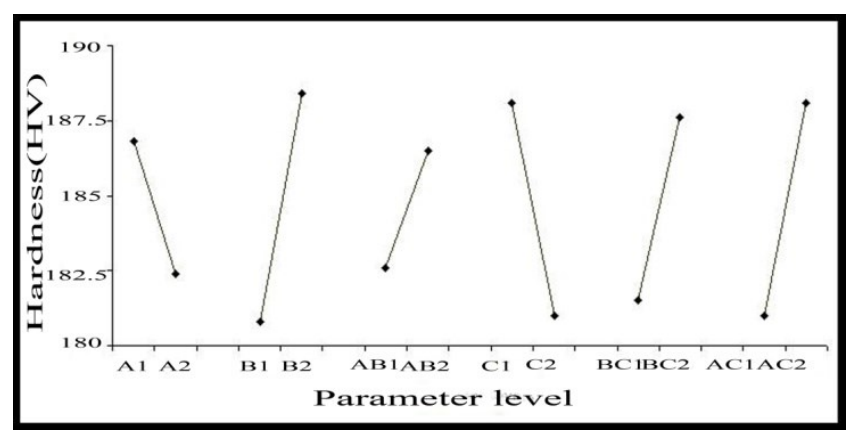

Fig. 4. Average values of hardness for each parameter at different levels

Table 7.

Average values of S/N data (tensile strength)

\begin{tabular}{lccc}
\hline & \multirow{2}{*}{$\begin{array}{c}\text { Process } \\
\text { parameters }\end{array}$} & \multicolumn{2}{c}{ Average values of tensile strength } \\
\cline { 2 - 4 } & $\mathrm{A}$ & Level 1 & Level 2 \\
\cline { 2 - 4 } & $\mathrm{B}$ & 57.04 & 57.30 \\
\cline { 2 - 4 } Tensile & $\mathrm{AB}$ & 56.89 & 57.46 \\
strength & $\mathrm{C}$ & 56.96 & 57.38 \\
\cline { 2 - 4 }$(\mathrm{S} / \mathrm{N}$ data $)$ & $\mathrm{BC}$ & 57.36 & 56.98 \\
\cline { 2 - 4 } & $\mathrm{AC}$ & 57.05 & 57.29 \\
\cline { 2 - 4 } & & 57.03 & 57.31 \\
\hline
\end{tabular}


Table 8.

Average values of mean data (tensile strength)

\begin{tabular}{lccc} 
& $\begin{array}{c}\text { Process } \\
\text { parameters }\end{array}$ & \multicolumn{2}{c}{ Average values of tensile strength } \\
\cline { 2 - 4 } & $\mathrm{A}$ & Level 1 & Level 2 \\
\hline \multirow{3}{*}{$\begin{array}{l}\text { Tensile } \\
\text { strength }\end{array}$} & $\mathrm{B}$ & 613.0 & 733.5 \\
\cline { 2 - 4 } $\begin{array}{l}\text { (mean } \\
\text { data) }\end{array}$ & $\mathrm{AB}$ & 706.8 & 746.8 \\
\cline { 2 - 4 } & $\mathrm{C}$ & 740.0 & 740.3 \\
\cline { 2 - 4 } & $\mathrm{BC}$ & 713.5 & 706.5 \\
\hline & $\mathrm{AC}$ & 711.8 & 733.0 \\
\hline
\end{tabular}

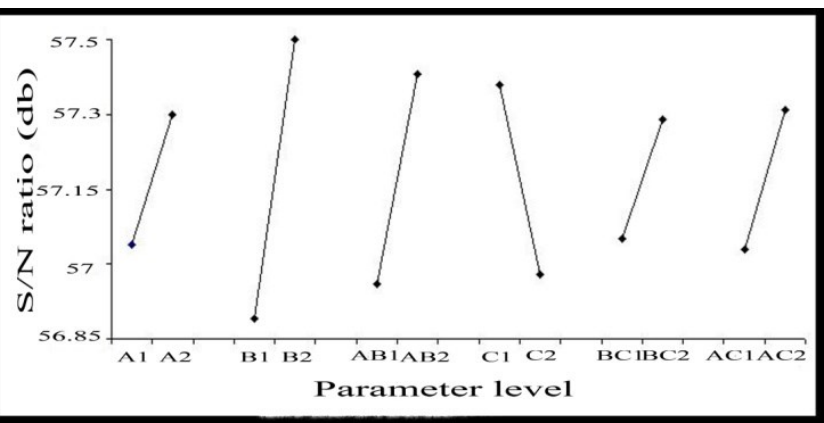

Fig. 5. Average values of $\mathrm{S} / \mathrm{N}$ ratios for each parameter at different levels (tensile strength)

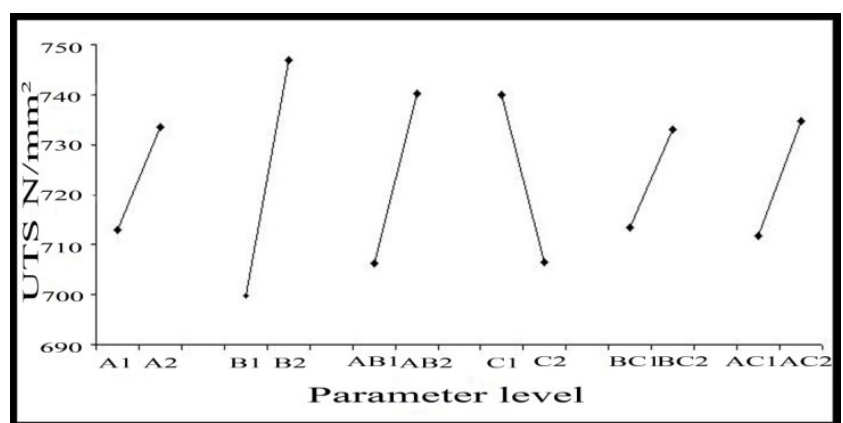

Fig. 6. Average values of tensile strength for each parameter at different levels

\subsection{Analysis of variance}

The ANOVA test [10-13] was used to determine the significance of each factor in the experiment and it estimates the experimental errors also. Furthermore it gives the percentage contribution of each factor in the experiment. The ANOVA for hardness and tensile strength is given in Table 9 and Table 10 respectively. It indicates that the effect of niobium addition is more than the other two factors

\subsection{Estimation of Optimum Hardness}

The level at which the maximum value of hardness obtained is the optimum level for that particular factor. In this experimental work, the optimum levels selected for each factor for obtaining the higher hardness are $\mathrm{A}_{2}, \mathrm{~B}_{2}, \mathrm{AB}_{2}, \mathrm{C}_{1}, \mathrm{BC}_{2}$ and $\mathrm{AC}_{2}$. The optimum value of hardness can be determinedusing the following expression [10-14]:

$\mu_{h}=A_{1}+B_{2}+A B_{2}+C_{1}+B C_{2}+A C_{2}-5 \bar{T}_{h}$

Table 9.

ANOVA Table for Hardness

\begin{tabular}{cccccc}
\hline Source & DOF & SS & V & F ratio & Contribution\% \\
\hline $\mathrm{A}$ & 1 & 76.56 & 76.56 & 5.91 & $7.34^{*}$ \\
\hline $\mathrm{B}$ & 1 & 232.56 & 232.56 & 17.96 & $22.36^{*}$ \\
\hline $\mathrm{AB}$ & 1 & 60.06 & 60.06 & 4.64 & $5.76^{*}$ \\
\hline $\mathrm{C}$ & 1 & 203.06 & 203.06 & 15.68 & $19.48^{*}$ \\
\hline $\mathrm{BC}$ & 1 & 150.06 & 150.06 & 11.59 & $14.40^{*}$ \\
\hline $\mathrm{AC}$ & 1 & 203.06 & 203.06 & 15.68 & $19.48^{*}$ \\
\hline Error & 9 & 116.56 & 12.95 & & $11.18^{*}$ \\
\hline Total & 15 & 1041.94 & & 100.0 \\
\hline & $\begin{array}{l}\text { DOF: degree of freedom, SS: sum of squares, V: variance } \\
\text { * Significant at 95\% confidence level }\end{array}$
\end{tabular}

Table 10

ANOVA Table for Tensile Strength

\begin{tabular}{cccccc}
\hline Source & DOF & SS & $\mathrm{V}$ & $\begin{array}{c}\mathrm{F} \\
\text { ratio }\end{array}$ & Contribution\% \\
\hline $\mathrm{A}$ & 1 & 1681.0 & 1681.0 & 4.8 & $6.30^{*}$ \\
\hline $\mathrm{B}$ & 1 & 8836.0 & 836.0 & 25.21 & $33.44^{*}$ \\
\hline $\mathrm{AB}$ & 1 & 4624.0 & 4624.0 & 3.19 & $17.50^{*}$ \\
\hline $\mathrm{C}$ & 1 & 4489.0 & 4489.0 & 12.81 & $16.96^{*}$ \\
\hline $\mathrm{BC}$ & 1 & 1521.0 & 1521.0 & 4.34 & $5.75^{*}$ \\
\hline $\mathrm{AC}$ & 1 & 2116.0 & 2116.0 & 6.04 & $8.38^{*}$ \\
\hline Error & 9 & 3154.0 & 350.4 & & $11.67^{*}$ \\
\hline Total & 15 & 26421.0 & & 100.0 \\
\hline $\begin{array}{l}\text { DOF: degree of freedom, SS: sum of squares, } \mathrm{V}: \text { variance } \\
\text { * Significant at 95\% confidence level }\end{array}$ \\
\hline
\end{tabular}

Where $\mu_{\mathrm{h}}$ is mean value of the hardness, $\bar{T}_{h=184.5 \mathrm{HV}}$ (Average) from Table 4 and $A_{1}, B_{2}$ and $C_{1}$ are the average values of the

\subsection{Estimation of Optimum Tensile Strength}

The near optimum range of process parameter levels can be obtained by using Taguchi's method. The level at which the maximum value of tensile strength obtained is the optimum level for that particular factor. In this experimental work, the optimum levels selected for each factor for obtaining the higher tensile strength are $A_{2}, B_{2}, A_{2}, C_{1}, B_{2}$ and $A_{2} .$. The optimum value of tensile strength can be determined using the following expression [10-14]:

$\mu_{T S}=A_{2}+B_{2}+A B_{2}+C_{1}+B C_{2}+A C_{2}-5 \bar{T}_{T S}$

Where $\mu_{\mathrm{TS}}$ is mean value of the tensile strength, $\bar{T}_{T S}=723.25$ $\mathrm{N} / \mathrm{mm}^{2}$ (Average) from Table 4 and $\mathrm{A}_{2}, \mathrm{~B}_{2}$ and $\mathrm{C}_{1}$ are the average values of the tensile strength. $\mu_{\mathrm{TS}}=812 \mathrm{~N} / \mathrm{mm}$ 


\subsection{Confidence Interval}

The ANOVA calculations depend on the sample size used in the experiment. Improvement of the estimate is precise when more heats are sampled. The confidence interval (CI) is known as a range within which the result is likely to fall for a given level of confidence. The confidence interval (CI) for the estimated hardness and tensile strength can be calculated using the equation (4):

$$
C I=\sqrt{F_{\alpha}\left(1, f_{e}\right) V_{e}\left[\frac{1}{n_{e f f}}+\frac{1}{R}\right]}
$$

where $F_{\alpha}(1, f e)=$ the $F$ ratio at a confidence level $(1-\alpha)$ against DOF 1 and error DOFfe, $V_{e}=$ error variance, $\eta_{e f f}$ is the effective number of replications can be computed using the equation (5) :

$$
n_{\text {eff }}=\frac{N}{1+(\text { Total DOF in the estimationof mean })}
$$

$\mathrm{N}=$ total number of results $(2 \mathrm{X} 8=16), \mathrm{R}=$ sample size for confirmation experiment. $=3$.

The following values are used to find the confidence interval (CI) for hardness:

$\mathrm{V}_{\mathrm{e}}=12.95$ (Table 7), Total DOF in estimation of mean $=6, \mathrm{n}_{\mathrm{eff}}$ $=3, \mathrm{~F}_{0.05}(1,8)=5.32$ (tabulated)

The confidence interval (CI) at $95 \%$ is $+/-7.28$

Thus the predicted optimum hardness is $195.72<\mu_{\mathrm{h}}<210.28 \mathrm{HV}$.

The following values are used to find the confidence interval (CI) for tensile strength:

$\mathrm{V}_{\mathrm{e}}=350.4$ (Table 7), Total DOF in estimation of mean $=6, \mathrm{n}_{\mathrm{eff}}$ $=3, \mathrm{~F}_{0.05}(1,8)=5.32$ (tabulated)

The confidence interval (CI) at $95 \%$ is $+/-37.88$

Thus the predicted optimum tensile strength is $714.2<\mu_{\mathrm{TS}}$ $<849.88 \mathrm{~N} / \mathrm{mm}^{2}$.

\subsection{Microstructure}

The microstructures of the non micro alloyed and micro alloyed normalized cast steels are shown in the fig.7. Variations in pearlite and ferrite contents were noticed which resulted in higher hardness, tensile strength and lower elongation and toughness. Non microalloyed normalized cast steels consists pearlite colonies in the ferrite matrix as shown in figure 7 (a) [15].
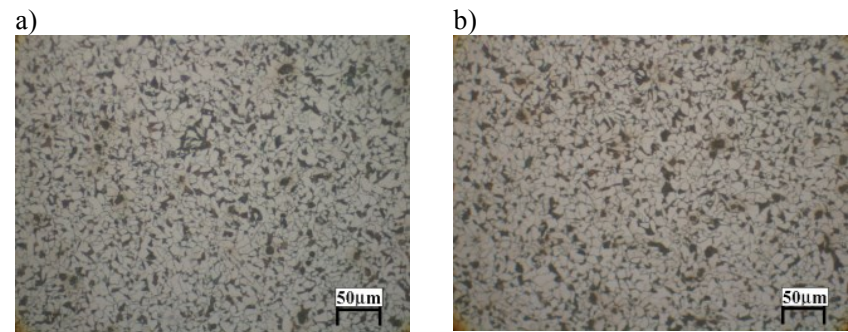

c)

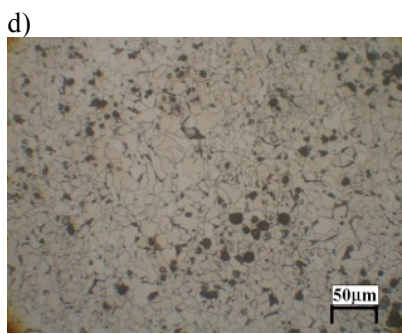

Fig. 7. Optical Micrographs of the experimental steels. (a) As cast, (b) Vanadium, (c) Niobium, (d) Titanium

Figure 7 (b) presents the effect of addition of vanadium which forms the pearlitee colonies in the ferrite matrix and larger grains.. Micro-alloyed with niobium have the finest and uniform microstructure. Finest pearlite colonies distributed uniformly in the ferrite. The grains of niobium micro-alloyed steels become finer as shown in figure 7(c) due to this hardness and tensile strength were increased when compared with other micralloyed normalized cast steels. Addition of titanium yields non-uniform distribution of pearlite colonies in ferrite matrix as shown in figure 7 (d), hardness and tensile strength were found lower compared with niobium microalloyed cast steels. Increased size of ferrite and pearlite grains was obtained.

\subsection{Ductile Properties}

The experimental results of ductile properties obtained from impact and tensile tests are listed in table 11. Toughness and percentage elongation of the niobium micro alloyed normalized cast steel was found more compared with other trials. Since the micro structure of niobium micro alloyed steel contains uniform distribution of pearlite colonies in the ferrite matrix.

Table 11.

Ductile Properties of trials

\begin{tabular}{ccc}
\hline Trial No. & Toughness (Joules) & \% Elongation \\
\hline 1 & 42.5 & 26.5 \\
\hline 2 & 14.5 & 13.5 \\
\hline 3 & 28.5 & 22.5 \\
\hline 4 & 20.5 & 14.5 \\
\hline 5 & 21.5 & 16 \\
\hline 6 & 15.5 & 16 \\
\hline 7 & 17.5 & 19 \\
\hline 8 & 14.5 & 17.5 \\
\hline
\end{tabular}




\subsection{Confirmation of Experiment}

The selected factors and their final chosen levels are to be verified with a confirmation experiment. The average result of the confirmation experiment is to be within confidence limits. If this average result is within the confirmation experiment, then the selected factors were significant and their chosen levels for getting the result were properly chosen. On contrary, if this average result is not within the confidence limits, then the selected factors or their levels in the experiment to obtain the required result were wrong. In such cases further experiments are required.

In this work, three confirmation experiments were conducted with the optimum additions of the micro alloying elements found by the investigation. The mean value of the tensile strength and hardness of micro-alloyed normalized cast steel at the optimum micro-alloying addition was found $760 \mathrm{~N} / \mathrm{mm}^{2}$ and $200 \mathrm{HV}$ respectively which are within the confidence interval of predicted optimum tensile strength and hardness. Thus the selected factors and their levels were found significant in this experiment to obtain the required result.

\section{Conclusions}

In this work, Taguchi's concept was applied to determine the optimum levels of the micro-alloying additions of vanadium, niobium and titanium for getting higher hardness and tensile strength in the normalized micro-alloyed cast steel. Based on the optimization, the following conclusions can be drawn.

Niobium microalloyed normalized cast steel has higher hardness $(200 \mathrm{HV})$, higher tensile strength $(780 \mathrm{MPa})$, higher elongation (22.5\%) and higher impact toughness (28.5 Joules).

Micro-alloyed with niobium normalized cast steel have the finest and uniform microstructure. Finest pearlite colonies distributed uniformly in the ferrite.

In the non-micro-alloyed normalized cast steel, the hardness and tensile strength obtained was $175 \mathrm{HV}$ and $650 \mathrm{~N} / \mathrm{mm}^{2}$ respectively.

According to the analysis of variance (ANOVA), the effect of niobium addition was the most significant on hardness and tensile strength in the normalized cast steel. Confirmatory experiments were conducted to verify the predicted optimum condition. The predicted value and confirmation value of the hardness and tensile strength of the micro alloyed normalized cast steel were found close to each other.

\section{References}

[1] Seshan, S. (1999). Studies on Microalloyed Cast Steels. Proceedings of the Sixth Asian Foundry Congress. Calcutta. 181-187.

[2] Jana, B.D., Chakrabarti, A.K. \& Ray, K.K. (1993). Study of Cast Microalloyed Steels. Materials Science and Technology. 80-86. DOI:10.1179/026708303225008644.

[3] Najafi, H., Rassizadehghani, J. \& Halvaaee, A. (2007). Mechanical Properties of As Cast MicroalloyedSteels Containing V, $\mathrm{Nb}$ and Ti. Material Science and Technology. 23(6), 699-705. DOI: 10.1179/174328407X179755

[4] Rassizadehghani, J., Najafi, H., Emamy, M. \& Saeen, E. (2007). Mechanical Properties of V, Nb and Ti Bearing As Cast Micro Alloyed Steels. Journal of Material Science and Technology. 23(6), 779- 784.

[5] Kalandyk, B., Matysiak, H. \& Głownia, J. (2004). Microstructure Strength Relationship in Microalloyed Cast Steels. Reviews on Advanced Material Science. 8(1),44-48.

[6] Guang Xu, Xiaolong Gan, Guojun Ma, Fengluo \& Hang Zoe. (2010). The Development of Ti Alloyed High Strength Micro alloy Steel. Materials and Design. 31, 2891-2896. DOI: 10.1016/j.matdes 2009.12.032.

[7] Rasouli, D., Kamanah Asl, Sh., Akbar Zadeh, G.H. \& Daneshi, (2008). Optimization Of Mechanical Properties of a Micro Alloyed Steel. Materials and Design. 30(6), 21672172. DOI: 10.1016/j.matdes 2008.08.024.

[8] Najafi, H., Rassizadehghani, J. \& Asgari, S. (2008). As Cast Mechanical Properties of Vanadium/Niobium Microalloyed Steels. Materials Science and Engineering: A. (1-2), 1-7. DOI: 10.1016/J.MSEA.2007.08.057

[9] Kaiming, W.U., Zigang, L.I., Guo, A.M., Xianlai, H.E., Zhang, L., Fang, A. \& Cheng, L. (2006). Microstructure Evolution in a Low Carbon Nb-Ti Microalloyed Steel. ISIJ International. 46 (1), 161- 165.

[10] Ross, P.J. (2005). Taguchi Techniques for Quality Engineering. ( $2^{\text {nd }}$ ed.). NewDelhi: Tata McGraw hill Publishing Company Ltd.

[11] Roy, R.K. (1990). A Primer on The Taguchi Method. Society of Manufacturing Engineers. Dearbon. Michigan.

[12] Amitava Mitra, (1998). Fundamentals of Quality Control and Improvement. (2nd ed.). Prentice Hall. New Jersy.

[13] Bendel, A., Disney, J., Pridmore, W.A. (1989). Taguchi Methods: Applications in World Industry. IPS Publication, UK.

[14] Bhatt, A. \& Parappagoudar, M.B. (2015). Modeling and Analysis of Mechanical Properties in Structural Steel-DOE Approach. Archives of Foundry Engineering. 4(15), 5-12. DOI: 10.1515/AFE-2015-0069.

[15] Gao, W.L., Leng, Y., Fu, D.F. \& Teng, J. (2016). Effects of niobium and heat treatment on microstructure and mechanical properties of low carbon cast steels. Materials and Design. 114-123. DOI:10.1016/j.matdes.2016.05.057. 